\title{
Neonatal Intra-Ventricular-Hemorrhage prevention in premature at $<$ 30 weeks gestational Age
}

Authors

Angela B. Hoyos 1,2, a, Pablo Vasquez-Hoyos 3,4,5, b.

Affiliations

1. MD. Division of Neonatology, Clinica del Country, Bogota, DC, Colombia.

2. Professor of Pediatrics, Universidad El Bosque, Bogota, Colombia.

3. MD, MSc. Sociedad de Cirugía, Hospital de San José, Bogota, Colombia.

4. Department of Pediatrics. Universidad Nacional de Colombia, Bogota, Colombia.

5. Department of Pediatrics. Fundación Universitaria de Ciencias de la Salud, Bogota, Colombia. ORCID:

a. https://orcid.org/0000-0002-5403-3268

b. https://orcid.org/0000-0002-4892-5032

Corresponding autor: Dr. Angela Hoyos; Unidad de Neonatología, Clínica del Country, Cra 15 \# 84-13, Bogotá, Colombia. Email: angela.hoyos@ clinicadelcountry.com.

Funding source: We did not receive funding, only the time of the authors.

\section{Abstract}

Introduction: Intraventricular Hemorrhage (IVH) is a devastating condition mostly in preterm infants at $<30$ weeks GA with large morbidities and mortality usually in the first 72 hours after birth. Prevention seems to be the only way to completely deal with this problem.

Material and method: We design a before and after observational study and measured the incidence of IVH when a minimum manipulation protocol was implemented at the Clínica del Country (CDC) unit. We also compare these findings to those of other units in the EpicLatino network. All patients born $<30$ weeks GA with less than 2 days of age, who survived at least 3 days, and had a neuroimaging taken were included.

Results: We collected data from 46 cases before, 40 after implementation, and 203 cases from the EpicLatino registry. Demographic characteristics were very similar in the post-intervention with few statistically significant differences in antenatal steroid use, prolonged rupture of membranes, vaginal deliveries, suspended chorioamnionitis. We found a significant reduction in IVH after the protocol was 
implemented with only $5(7.5 \%)$ cases post-intervention compared to 19 (29.4\%) case before, and when compared to the $81(39.1 \%)$ cases in the registry, $\mathrm{p}<0.001$. Most of the cases that occurred in the postintervention occurred before admission to the unit due to obstetric trauma.

Discussion: If a well-controlled delivery minimizing obstetric trauma is achieved, a minimal manipulation protocol appears to significantly decrease the incidence of HIV. Controlled, multicenter studies are still required to confirm these findings.

\section{Key words:}

Intraventricular Hemorrhage, Very preterm infants, Epiclatino registry, Obstetric trauma, Minimal manipulation protocol.

\section{Main manuscript}

\section{Introduction}

Intra-Ventricular-Hemorrhage (IVH) is a devastating condition mostly in preterm infants < 30 weeks gestational age (GA) at birth, with large morbidities and mortality. ${ }^{1-3}$ The timing of the IVH appears to occur in the first 6 hours of life ${ }^{4,5}$ but it can continue to develop and most cases are found in the first 72 hours after birth. ${ }^{6}$

Hemorrhage at delivery due to obstetric complications probably accounts for many of these cases. Observational studies show that elective cesarean section reduces the risk of IVH in preterm infants $<30$ weeks GA when they present with preterm labor. ${ }^{7}$ Other risk factors such as germinal matrix immaturity and fluctuations in the cerebral blood flow are described. ${ }^{8,9}$ Clinically, low birth weight or low gestational age, lack of antenatal corticosteroids, maternal chorioamnionitis, low Apgar score $(<5)$ at 5 min, respiratory distress syndrome, early onset sepsis, hypercapnia or $\mathrm{PCO}_{2}$ fluctuations, inotropes or boluses, metabolic disorders, opioids infusions, and bicarbonate therapy are also associated with IVH. ${ }^{6,7,10}$

Prevention seems to be the only way to reduce this phenomenon. The prevention of IVH in this age group is focuses on strategies such as prenatal corticosteroids, ${ }^{11}$ cesarean delivery, ${ }^{7}$ careful extraction and other nurse practices, ${ }^{12}$ but it still has an unacceptably high incidence in this population. 
A new strategy for neuroprotection was develop years ago under the name "Drive to Zero IVH Prevention Project"13 and was presented in one of the EpicLatino conferences. Our unit decided to adapt this project as a quality improvement practice. In this study we measured the results of this project by comparing cases before and after the intervention and we also used the EpicLatino registry as a concurrent cohort.

\section{Material and method}

Study design

Observational nonconcurrent cohort study querying a prospectively collected registry (EpicLatino).

\section{Setting}

Epiclatino is a registry of neonatal intensive care units in Latin America, based on the CNN (Canadian Neonatal Network) collection instrument for quality improvement. ${ }^{14}$ Clínica del Country (CDC) is a third level private general hospital located in Bogota, Colombia with a third level neonatal unit with a high incidence of high-risk deliveries. In October 2017, we designed and adapt a strategy for minimum manipulation to the existing prevention strategies in place. At the end we came up with this approach (Table 1).

\section{Subjects}

All patients $<30$ weeks of GA less than 2 days old were included in the new strategy at CDC, for this study we included patients who survived at least 3 days and had aneuroimaging taken (November 2017 to discharge by August 31 2021). For comparison, other cases from the other EpicLatino units from 2018 and 2019 and cases at the CDC from previous years (January 2016- October 2017) also born with $<30$ weeks GA and surviving 3 days and had a neuroimage were selected for analysis.

\section{Variables}

We define IVH grade 1 and 2 as hemorrhage in the germinal matrix and/or ventricles, without intraventricular dilation or periventricular hemorrhage. Grades 3 and 4 were defined as bleeding with ventricular dilatation or bleeding outside the ventricles. We also capture birthweight, gestational age (GA), sex, inborn/outborn, temperature at admission, prenatal corticosteroids, prolonged ( $>24 \mathrm{~h})$ rupture of membranes (ROM), delivery (vaginal or cesarian), suspected chorioamnionitis, Apgar score at 5 minutes, deaths after day 3 and treated patent ductus arteriosus (PDA). 


\section{Analysis}

We gathered all available cases in a convenience sample with no sample size calculation. All the parameters were compared within the two time periods and the EpicLatino registry using Chi-square test by Fischer's exact method or Kruskal-Wallis rank test, depending on the type of variable. A p value less that 0.05 was considered significant.

\section{Ethics}

EpicLatino registry is an approved registry by the local institutional review board at each center with a waiver of informed consent as it gathers non identifiable data for research and quality improvement programs. This manuscript has been also approved by an ethic comity as a minimal risk and wavered the inform consent.

\section{Results}

We collected a total of 46 cases at CDC before and 40 post-implementations, and we gather 203 cases from the EpicLatino registry (2018-2019). Anthropometric and demographic characteristics are shown in table 2. Of note, temperature at admission and prolonged ROM were statistically different due in the before intervention group. On the other hand, prenatal corticosteroids, and suspected chorioamnionitis were statistically different in EpicLatino group. Vaginal deliveries and treated PDA were statistically different in both pre-intervention and EpicLatino groups.

Regarding IVH, distribution was statistically significant among the groups (Figure 1). There were one grade 1-2 hemorrhage and 2 grade 3-4 during the post-intervention period. Both grade 3-4 happened during very traumatic deliveries with multiples hematomas around the head, body, and extremities.

\section{Discussion}

We found a statistically significant reduction in the incidence of IVH in the post-intervention group when compere to the historical cohort (before) and the EpiLatino registry, and both severe cases were related to delivery trauma. The hemorrhage during delivery is well described ${ }^{15}$ and must be prevented by the obstetric team.

We found some factors that could explain some of the difference in the intraventricular hemorrhagic results. Temperature at admission as a marker of moderate/severe acute transitional hypothermia has been associated with increased risk of intraventricular hemorrhage (from $6.8 \%$ in 
normal temperature to $13 \%$ with moderate/severe hypothermia), ${ }^{16}$ but not in all studies. ${ }^{17}$ Prolonged ROM has been associated with increased risk of $\mathrm{IVH}^{18}$ but it is difficult to separate it from the risk of prematurity, so it is not easy to evaluate how much ROM > 24 hours can increase the risk of IVH. Lack of prenatal corticosteroids increases the risk of $\mathrm{IVH},{ }^{11}$ and can explain in part the increased risk of IVH in the EpicLatino group. On the other hand, suspected chorioamnionitis also increases de risk of $\mathrm{IVH}^{11}$ in the EpicLatino group but decreases the risk in the historical cohort since it is lower than the post-intervention group. The relation between vaginal delivery and $\mathrm{C}$-section may also favor the post-intervention group, especially compared to EpicLatino $^{7}$ but more PDA treatment in both control groups could favor IVH prevention since in the post-intervention group only $10 \%$ were treated even if some studies question its significance. ${ }^{19}$ We believe that this large difference in IVH incidence is not explain by the difference in these factors described above but in the protocol applied.

Our study has limitations as is not a randomized control study, the variables affecting the incidence of IVH could not be properly control and this could explain at least part of the results. Large randomized clinical trials are needed to confirm our findings.

\section{Conclusion}

We believe that the gentle handling described with minimal manipulation and unnecessary laboratories and therapies is linked to reducing the incidence of HIV in this population. Modification of a single parameter, as observed in randomized control studies, will probably not change the incidence of IVH significantly, but a set of modifications in many as observed in this quality improvement protocol may decrease the incidence of IVH. Large multicenter clinical trials are needed to confirm these findings.

Acknowledgment: The authors are indebted to all parents and their infants. We thank all nurses and doctors and study centers who participate in the Database.

Collaborators: EpicLatino registry. Gonzalez, D: Clínica Latino, Cuenca, Ecuador. Africano M: Clínica Materno Infantil San Luis, Bucaramanga, Colombia. Jara E: Clínica Santa Bárbara, Quito, Ecuador. Gonzalez E: Clínica Somer, Rio Negro, Colombia. Villegas C: Hospital Central Dr. Ignacio Morones Prieto, San Luis Potosí, México. Torres S: Hospital Centro Policlinico del Olaya, 
Bogota, Colombia. Burbano CG: Hospital Civil de Ipiales, Ipiales, Colombia. Delgado V: Hospital de los Valles, Quito, Ecuador. Roge H: Hospital Español de Mendoza, Mendoza, Argentina. Arias D: Hospital San José, Bogotá, Colombia. Belzu MA. Hospital Dr. Florencio Escardó, Tigre, Argentina. Zambosco GA. La Plata, Argentina. Aguinaga F: Hospital Metropolitano, Quito, Ecuador. Alarcon C. Hospital Militar Central, Bogotá, Colombia. Castellanos JC: Hospital Regional Universitario de Colima, Colima, Mexico. Calero M: Hospital San Francisco de Quito, Quito, Ecuador. Cruz B: Hospital Prov. General Docente Riobamba, Riobamba, Ecuador. Martinini MI: Maternidad Nuestra Sra. de las Mercedes, Tucuman, Argentina. Fernandez M: Hospital Santísima Trinidad, Asunción, Paraguay. Duque N: St. Elisabeth Hospital. Willemstad, Curaçao.

\section{Conflict of Interest: We have no conflict of interest and nothing to declare.}




\section{Reference}

1. Leijser LM, de Vries LS. Preterm brain injury: Germinal matrix-intraventricular hemorrhage and posthemorrhagic ventricular dilatation. Handb Clin Neurol. 2019;162:173-199. doi:10.1016/B978-0-444-640291.00008-4

2. Hinojosa-Rodríguez M, Harmony $T$, Carrillo-Prado $C$, et al. Clinical neuroimaging in the preterm infant: Diagnosis and prognosis. Neuroimage Clin. 2017;16:355-368. doi:10.1016/j.nicl.2017.08.015

3. Tan AP, Svrckova P, Cowan F, Chong WK, Mankad K. Intracranial hemorrhage in neonates: A review of etiologies, patterns and predicted clinical outcomes. Eur J Paediatr Neurol. Jul 2018;22(4):690-717. doi:10.1016/j.ejpn.2018.04.008

4. Al-Abdi SY, Al-Aamri MA. A Systematic Review and Meta-analysis of the Timing of Early Intraventricular Hemorrhage in Preterm Neonates: Clinical and Research Implications. J Clin Neonatol. Apr 2014;3(2):76-88. doi:10.4103/2249-4847.134674

5. Al-Abdi SY, Al-Aamri MA. Timing of Intraventricular Hemorrhage in Preterm Neonates. J Pediatr. Aug 11 2021;doi:10.1016/j.jpeds.2021.07.063

6. Goswami IR, Abou Mehrem A, Scott J, Esser MJ, Mohammad K. Metabolic acidosis rather than hypo/hypercapnia in the first 72 hours of life associated with intraventricular hemorrhage in preterm neonates. J Matern Fetal Neonatal Med. Dec 18 2019:1-9. doi:10.1080/14767058.2019.1701649

7. Humberg A, Härtel C, Paul P, et al. Delivery mode and intraventricular hemorrhage risk in very-low-birthweight infants: Observational data of the German Neonatal Network. Eur J Obstet Gynecol Reprod Biol. May 2017;212:144-149. doi:10.1016/j.ejogrb.2017.03.032

8. Hefti MM, Trachtenberg FL, Haynes RL, Hassett C, Volpe JJ, Kinney HC. A Century of Germinal Matrix Intraventricular Hemorrhage in Autopsied Premature Infants: A Historical Account. Pediatr Dev Pathol. 2016 Mar-Apr 2016;19(2):108-14. doi:10.2350/15-06-1663-OA.1

9. Vesoulis ZA, Flower AA, Zanelli S, et al. Blood pressure extremes and severe IVH in preterm infants. Pediatr Res. 01 2020;87(1):69-73. doi:10.1038/s41390-019-0585-3

10. Khanafer-Larocque I, Soraisham A, Stritzke A, et al. Intraventricular Hemorrhage: Risk Factors and Association With Patent Ductus Arteriosus Treatment in Extremely Preterm Neonates. Original Research. Frontiers in Pediatrics. 2019-October-22 2019;7(408)doi:10.3389/fped.2019.00408

11. McGoldrick E, Stewart F, Parker R, Dalziel SR. Antenatal corticosteroids for accelerating fetal lung maturation for women at risk of preterm birth. Cochrane Database Syst Rev. 1225 2020;12:CD004454. doi:10.1002/14651858.CD004454.pub4

12. de Bijl-Marcus K, Brouwer AJ, De Vries LS, Groenendaal F, Wezel-Meijler GV. Neonatal care bundles are associated with a reduction in the incidence of intraventricular haemorrhage in preterm infants: a multicentre cohort study. Arch Dis Child Fetal Neonatal Ed. Jul 2020;105(4):419-424. doi:10.1136/archdischild-2018-316692

13. Ryan M, Lacaze-Masmonteil T, Mohammad K. Neuroprotection from acute brain injury in preterm infants. Paediatr Child Health. Jul 2019;24(4):276-290. doi:10.1093/pch/pxz056

14. EpicLatino. Epiclatino Repport 2019. 2019:198-199. https://www.epiclatino.co/report-2019

15. Lim J, Hagen E. Reducing Germinal Matrix-Intraventricular Hemorrhage: Perinatal and Delivery Room Factors. Neoreviews. 08 2019;20(8):e452-e463. doi:10.1542/neo.20-8-e452

16. Miller SS, Lee HC, Gould JB. Hypothermia in very low birth weight infants: distribution, risk factors and outcomes. J Perinatol. Apr 2011;31 Suppl 1:S49-56. doi:10.1038/jp.2010.177

17. Audeh $S$, Smolkin $T$, Bental $Y$, et al. Does admission hypothermia predispose to intraventricular hemorrhage in very-low-birth-weight infants? Neonatology. 2011;100(4):373-9. doi:10.1159/000327370

18. Gezer A, Parafit-Yalciner E, Guralp O, Yedigoz V, Altinok T, Madazli R. Neonatal morbidity mortality outcomes in pre-term premature rupture of membranes. J Obstet Gynaecol. Jan 2013;33(1):38-42. doi:10.3109/01443615.2012.729620 
19. Mitra S, Scrivens A, von Kursell AM, Disher T. Early treatment versus expectant management of hemodynamically significant patent ductus arteriosus for preterm infants. Cochrane Database Syst Rev. 12 10 2020;12:CD013278. doi:10.1002/14651858.CD013278.pub2

20. Carroll K, Kumar P, Prazad P, Mohammad K, Raghavan A, Wang H. Midline Head Positioning for Prevention of Intraventricular Hemorrhage (IVH) in Infants Born at 23-28 weeks gestation: a multicenter retrospective cohort stud. Pediatrics. 2019;144(2 MeetingAbstract):660-660.

doi:10.1542/peds.144.2_MeetingAbstract.660 
Table 1 Minimal manipulation protocol

Old strategies

- Regulated temperature and high humidity (80\%)

- Umbilical catheters when possible

- No PDA therapy or Echo if possible

- Routine therapy:

- Hydrocortisone $0.5 \mathrm{mg} / \mathrm{kg} /$ day in less than 27 weeks GA

- Erythropoietin $1200 \mathrm{U} / \mathrm{Kg} /$ week

- Caffeine

- Parenteral nutrition with fluids $70 \mathrm{cc} / \mathrm{K} / \mathrm{d}$

- Glucose 4mg/K/min

- Protein $4 \mathrm{~g} / \mathrm{k} / \mathrm{d}$

- Lipids $3 \mathrm{~g} / \mathrm{K} / \mathrm{d}$

- Trophic feeding (1-3 mL q. 3 hours)

- Probiotics

New strategies added

- Ventilatory parameters as needed and volume ventilation when possible.

- Only one routine fiscal exam a day. No routine measurements or weight

- Maintain neutral head position ${ }^{20}$ and bed elevated 30 degrees.

- Only 1 blood pressure measurement per shift.

- No keel prick measurements (glucose measurement once a day within blood gases).

- Continuous dim light less than 20 Lux when possible and noise level less than 45 dB.

- Minimal touching except to clean perinatal area and change dippers when needed.

- No vasoactive medication or boluses except in extreme cases. 
Table 2. Anthropometric and demographic characteristics

\begin{tabular}{|c|c|c|c|c|}
\hline \multirow[t]{2}{*}{ At Birth } & $\begin{array}{l}\text { Nov 2017- } \\
\text { 2021CDC }\end{array}$ & $\begin{array}{c}\text { 2016-2017 Oct } \\
\text { CDC }\end{array}$ & $\begin{array}{c}\text { Epiclarino } \\
2018-2019 \\
\text { without } \\
\text { CDC }\end{array}$ & \multirow[t]{2}{*}{$\mathrm{p}^{*}$} \\
\hline & n (\%) & n (\%) & n (\%) & \\
\hline $\mathrm{n}$ & 40 & 46 & 203 & \\
\hline \multicolumn{5}{|l|}{ Weight (gr) } \\
\hline $\begin{array}{c}<500 \\
500-750 \\
751-1000 \\
1001-1250 \\
1251-1500 \\
1500-1750\end{array}$ & $\begin{array}{c}2(5.0) \\
6(15.0) \\
12(30.0) \\
13(32.5) \\
7(17.5) \\
0(0) \\
\end{array}$ & $\begin{array}{c}0(0) \\
2(4.4) \\
22(47.8) \\
11(23.9) \\
9(19.6) \\
2(4.4) \\
\end{array}$ & $\begin{array}{c}0(0) \\
31(15.3) \\
69(34.0) \\
69(34.0) \\
31(15.3) \\
3(1.5) \\
\end{array}$ & 0.179 \\
\hline \multicolumn{5}{|l|}{ Gestational age (w) } \\
\hline $\begin{array}{r}23 \\
24 \\
25 \\
26 \\
27 \\
28 \\
29 \\
\end{array}$ & $\begin{array}{c}0(0) \\
0(0) \\
5(12.5) \\
3(7.5) \\
6(15.0) \\
11(27.5) \\
15(37.5) \\
\end{array}$ & $\begin{array}{c}0(0) \\
1(2.2) \\
6(13.0) \\
2(4.4) \\
13(28.3) \\
10(21.7) \\
14(30.4) \\
\end{array}$ & $\begin{array}{c}1(0.5) \\
9(5.0) \\
16(12.8) \\
38(31.5) \\
44(21.7) \\
47(23.2) \\
48(23.7) \\
\end{array}$ & 0.180 \\
\hline \multicolumn{5}{|l|}{ Sex } \\
\hline $\begin{array}{l}\text { Male } \\
\text { Female }\end{array}$ & $\begin{array}{l}24(60.0) \\
16(40.0)\end{array}$ & $\begin{array}{l}28(60.9) \\
18(39.1)\end{array}$ & $\begin{array}{c}96(48.3) \\
105(51.7)\end{array}$ & 0.226 \\
\hline Inborn & $39(97.5)$ & $45(96)$ & $194(95.6)$ & 1.000 \\
\hline $\mathrm{T}^{\mathrm{o}}$ at admission(med, IQR) & $36.4(0.85)$ & $35.8(0.9)$ & $36.0(1.4)$ & $0.0165 * *$ \\
\hline Prenatal corticosteroids & $39(97.5)$ & $44(96)$ & $161(79.3)$ & 0.016 \\
\hline ROM (>24h) & $6(15.0)$ & $2(4)$ & $31(15.25)$ & $<0.0001$ \\
\hline $\begin{array}{l}\text { Vaginal delivery } \\
\text { Cesarean section }\end{array}$ & $\begin{array}{c}3(7.5) \\
37(92.5) \\
\end{array}$ & $\begin{array}{l}5(10.9) \\
41(88)\end{array}$ & $\begin{array}{c}49(24.1) \\
154(75.9)\end{array}$ & 0.011 \\
\hline Suspected Chorio & $5(12.5)$ & $3(6)$ & $41(20.2)$ & $<0.0001$ \\
\hline Apgar 5' (mean $\pm \mathrm{SD})$ & $8(1.0)^{¥}$ & $8.0(0.9)^{¥}$ & $8(1.5)^{¥}$ & $0.055^{¥}$ \\
\hline Deaths $\geq 3$ days & $5(12.8)$ & $11(24)$ & $34(16.75)$ & 0.202 \\
\hline PDA (treated) & $4(10 \%)$ & $88(40 \%)$ & $13(28 \%)$ & 0.01 \\
\hline
\end{tabular}




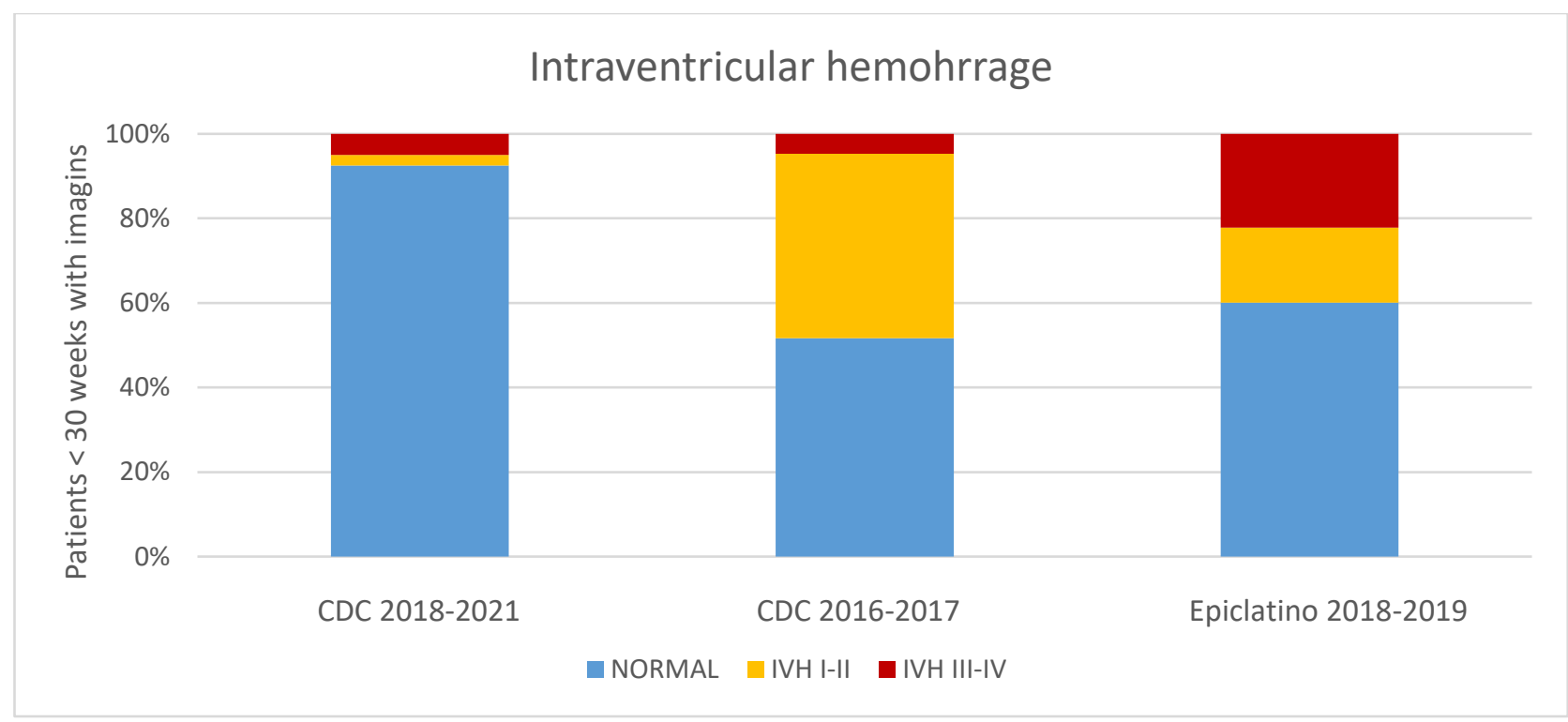

\begin{tabular}{|c|c|c|c|c|}
\hline \multirow{2}{*}{ IVH } & $\begin{array}{c}2018-2021 \\
\text { CDC }\end{array}$ & $\begin{array}{c}2016-2017 \\
\text { CDC }\end{array}$ & $\begin{array}{c}\text { Epiclarino } \\
2018-2019 \\
\text { without CDC }\end{array}$ & \multirow{2}{*}{$\mathrm{p}^{*}$} \\
\cline { 2 - 4 } & $\mathrm{n}(\%)$ & $\mathrm{n}(\%)$ & $\mathrm{n}(\%)$ & $<0.001$ \\
\hline NORMAL & $37(92.5)$ & $27(69.6)$ & $122(60.1)$ & 0.014 \\
\hline IVH I-II & $1(2.5)$ & $15(58.7)$ & $36(17.7)$ & 0.009 \\
\hline IVH III-IV & $2(5.0)$ & $4(6.3)$ & $45(22.2)$ & \\
\hline \multicolumn{2}{|l}{} \\
*Chi-square test by Fischer's exact method
\end{tabular}

Figure 1. IVH Results. CDC: Clinica del Country, IVH: Intraventricular Hemorrhage 